Article

\title{
Correlation of Biomechanical Alterations under Gonarthritis between Overlying Menisci and Articular Cartilage
}

\author{
Johannes Pordzik ${ }^{1, *}$, Anke Bernstein ${ }^{1}$, Julius Watrinet ${ }^{1}$, Hermann O. Mayr ${ }^{1,2}{ }^{\circledR}$, \\ Sergio H. Latorre ${ }^{1}\left(\mathbb{D}\right.$, Hagen Schmal ${ }^{1}$ (D) and Michael Seidenstuecker ${ }^{1, *(1)}$ \\ 1 G.E.R.N. Tissue Replacement, Regeneration \& Neogenesis, Department of Orthopedics and Trauma Surgery, \\ Medical Center-Albert-Ludwigs-University of Freiburg, Faculty of Medicine, \\ Albert-Ludwigs-University of Freiburg, Hugstetter Straße 55, 79106 Freiburg, Germany; \\ anke.bernstein@uniklinik-freiburg.de (A.B.); julius@watrinet.net (J.W.); \\ hermann.mayr@uniklinik-freiburg.de (H.O.M.); Sergio.Hernandez-Latorre@dzne.de (S.H.L.); \\ hagen.schmal@uniklinik-freiburg.de (H.S.) \\ 2 Schoen Clinic Munich Harlaching, Teaching Hospital of Paracelsus Medical University, \\ 5026 Salzburg, Austria \\ * Correspondence: johannes.prodzik@t-online.de (J.P.); michael.seidenstuecker@uniklinik-freiburg.de (M.S.)
}

Received: 30 October 2020; Accepted: 2 December 2020; Published: 4 December 2020

\begin{abstract}
Just like menisci, articular cartilage is exposed to constant and varying stresses. Injuries to the meniscus are associated with the development of gonarthritis. Both the articular cartilage and the menisci are subject to structural changes under gonarthritis. The aim of this study was to investigate biomechanical alterations in articular cartilage and the menisci under gonarthritis by applying an indentation method. The study assessed 11 menisci from body donors as controls and 21 menisci from patients with severe gonarthritis. For the simultaneous examination of the articular cartilage and the menisci, we only tested the joint surfaces of the tibial plateau covered by the corresponding menisci. Over the posterior horn of the meniscus, the maximum applied load-the highest load registered by the load cell—of the arthritic samples of $0.02 \pm 0.02 \mathrm{~N}$ was significantly greater $(p=0.04)$ than the maximum applied load of the arthritis-free samples of $0.01 \pm 0.01 \mathrm{~N}$. The instantaneous modulus (IM) at the center of the arthritic cartilage covered by the meniscus with $3.5 \pm 2.02 \mathrm{MPa}$ was significantly smaller than the IM of the arthritis-free samples with $5.17 \pm 1.88 \mathrm{MPa}(p=0.04)$. No significant difference was found in the thickness of the meniscus-covered articular cartilage between the arthritic and arthritis-free samples. Significant correlations between the articular cartilage and the corresponding menisci were not observed at any point. In this study, the biomechanical changes associated with gonarthritis affected the posterior horn of the meniscus and the mid region of the meniscus-covered articular cartilage. The assessment of cartilage thickness as a structural characteristic of osteoarthritis may be misleading with regard to the interpretation of articular cartilage's biomechanical properties.
\end{abstract}

Keywords: gonarthritis; meniscus; articular cartilage; biomechanical testing; mapping; indentation; instantaneous modulus; tissue biomechanics

\section{Introduction}

Arthritis is the most common joint disease, with the knee joint being one of the most frequently affected joints [1]. Constantly changing multidirectional and dynamic forces stress the knee joint daily [2]. One of the structural characteristics of arthritis is the loss of articular cartilage [3]. 
Degenerative changes are manifested in a softening and continuous thinning of the joint cartilage, potentially leading to the complete loss of cartilage [4].

The meniscus improves weight distribution in the knee joint by increasing the contact surface between the femoral condyles and the tibial plateau [5], serving as shock absorption [5,6] and protecting the joint cartilage beneath it [7]. Consequently, meniscus displacement or meniscus extrusion is a strong predictive factor for the loss of cartilage tissue, indicating that the biomechanical properties of the meniscus have failed [8,9]. This results in the current approaches that aim to preserve as much meniscus tissue as possible [10].

There exist a variety of forms of meniscus replacement, such as autogenous replacement, but also artificial implants. However, in contrast to articular cartilage replacement [11], a widely applicable meniscus replacement with clear scientifically proven efficacy is not yet available [12]. Given this gap in research, a deeper understanding of the biomechanical behavior of meniscus and cartilage tissue appears vital.

Thus far, for both menisci and joint cartilage, animal samples have predominantly been studied [13-18]. Previous biomechanical examination of the articular cartilage, as well as for the meniscus, included both unconfined compression tests $[16,19,20]$ and confined compression tests $[21,22]$. However, a complete mapping of the biomechanical properties of the tissue with a large number of measurement points was only possible to a limited extent [23,24], with exception of Seidenstuecker et al. [25], who examined the articular cartilage with a complete mapping of biomechanical properties. This was possible by using an indentation test. The main objective of the indentation test is to determine the instantaneous modulus (IM) and hardness of a sample. IM thus describes the ability of an elastic material to resist deformation under applied mechanical stress. The work from Sim et al. [26,27] and Seidenstuecker et al. [25] showed that automatic mapping of articular cartilage with Biomomentum Inc. technology (Montreal, QC, Canada) is possible.

Studies on human menisci and their corresponding articular cartilage concerning the difference between arthritic and arthritis-free samples are missing thus far.

The aim of this study was therefore to investigate the relationship between the biomechanical properties of the meniscus-covered cartilage and the corresponding menisci in the pathogenesis of osteoarthritis (OA) to better understand the role of the meniscus in the protection of the articular cartilage and contribute to the development of meniscus scaffolds.

\section{Materials and Methods}

A total of 32 menisci and the underlying articular cartilage were used for the measurements: 21 arthritic menisci and 11 arthritis-free samples.

The arthritic menisci were removed from the arthritic tibial plateau and the tissues were frozen within $24 \mathrm{~h}$ after surgery for total knee replacement (TKR) due to severe osteoarthritis [25].

The average age of the patients was $71.76 \pm 7.23$ years. Of the patients, 15 were female and 6 were male.

The arthritis-free samples originated from fresh frozen knees of body donors [25]. OA was excluded by specialists in orthopaedics and trauma surgery at the investigating hospital. During preparation of the arthritis-free samples by specialists in orthopaedics and trauma surgery, degenerative changes of the cartilage due to the patients age were observed. This includes softening and swelling as well as fibrillation of the cartilage surface in little areas. A further assessment including a grading system of these macroscopic changes has not been performed.

All arthritic samples were handled according to approved institutional ethics committee certificates (ethics vote 305/10 of the ethics commission of the Freiburg University Medical Center). 


\subsection{Indentation Testings}

The description of the biomechanical measurement methods concerning the articular cartilage is based on Seidenstuecker et al. [25]. The indentation test (DIN EN ISO 14577) was carried out first, followed by thickness measurement using the needle measuring method [28].

Biomechanical testing of the menisci and cartilage was carried out by means of indentation tests (DIN EN ISO 14577-1:2015) [29] (see Figure 1). A Mach-1 Model V500css test machine (Biomomentum Inc., Laval, Canada), a multiaxial load cell with $17 \mathrm{~N}$ MA 233 (ATI industrial Automation, Apex, NC, USA) for the menisci and a multiaxial load cell with 70 N Model FTIFPS1 (ATI industrial Automation, Apex, NC, USA) for the articular cartilage [25], and a Newport Motion Controller ESP 301 (Newport, Irvine, CA, USA) were used. These materials allow for the examination of soft tissue as well as the complete mapping of the tissue $[25,26,30]$. The menisci were fixed to the MA646 specimen holder (Biomomentum Inc., Laval, QC, Canada) by Loctide (Henkel AG and CoAG KGaA, Düsseldorf-Holthausen, Germany) according to physiological conditions and were then anchored in the testing device. For biomechanical testing of the articular cartilage of the tibial plateau, we first marked the meniscus-covered areas with tissue markers [25]. The samples were then fixed in the testing machine.

After that, the measuring points had to be determined. For this purpose, the glued menisci and tibial plateaus were recorded with a camera. In the Mach-1 Analysis Software Version 4.1.0.17 (Biomomentum, Montreal, QC, Canada), a position grid could then be projected on these images with which the measurements were taken [25].

The position grid was created mechanically for the arthritis-free meniscus and all tibial plateaus and manually adapted to the shape and size of the arthritic meniscus. The indentation test (DIN EN ISO 14577) was then carried out using a spherical indenter MA680 (Biomomentum Inc., Laval, QC, Canada) with a diameter of $1 \mathrm{~mm}$ [25]. In this way, the entire tissue can be tested. The maximum applied load was defined as the highest load registered by the load cell per measuring point. An average of 45 measuring points was distributed over the meniscus. When the articular cartilage was tested in the same way as the meniscus, an average of 35 measuring points was distributed over the entire tibial plateau.

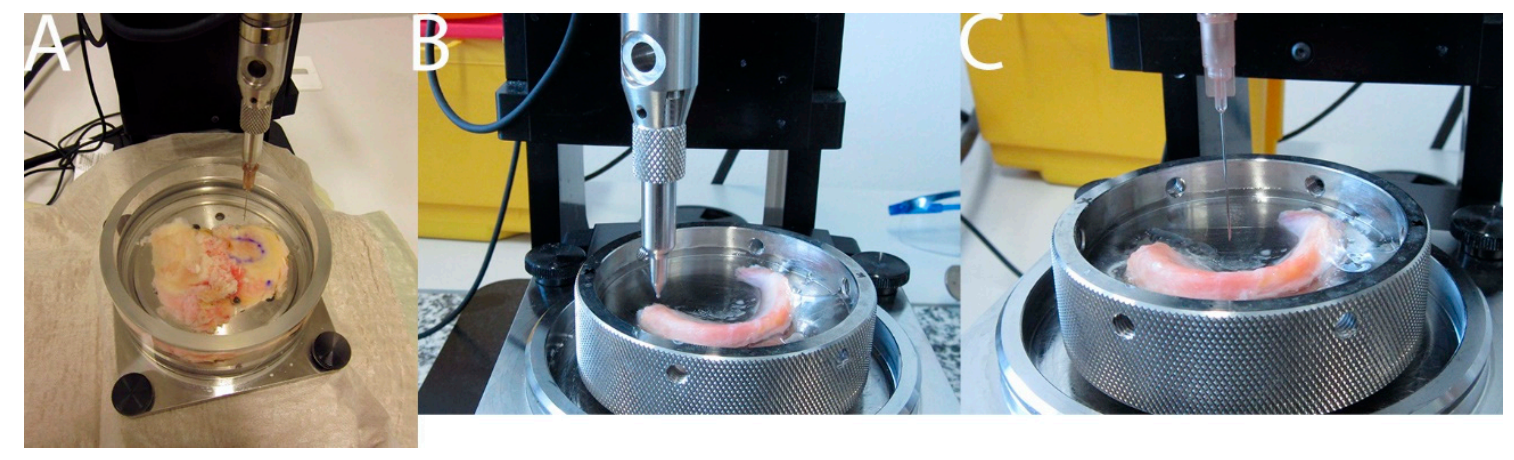

Figure 1. (A) Mach-1 thickness measurement by needle method (joint cartilage); (B) Mach-1 Indentation (meniscus); (C) Mach-1 thickness measurement by needle method (meniscus).

Since meniscus and articular cartilage differ in their biomechanical properties, the testing criteria differ. The testing criteria chosen are in the range of previous studies $[25,26]$. The meniscus is less stiff than the cartilage. Therefore, a $0.1 \mathrm{~mm} / \mathrm{s}$ faster indentation speed was chosen in comparison to the indentation speed of the cartilage [25]. The articular cartilage lies flat on the subchondral bone. Therefore a $0.1 \mathrm{~mm}$ higher indentation depth was chosen. Since the meniscus was glued on the metal, we selected a smaller depth. Otherwise, the indenter could touch the metal before reaching the predefined indentation depth. Thus, following testing criteria were used: 
The following criteria were used to test the meniscus: Poisson ratio: 0.5 , contact criterion: $0.1 \mathrm{~N}$, predefined indentation amplitude: $0.2 \mathrm{~mm}$, indentation speed: $0.2 \mathrm{~mm} / \mathrm{s}$, and relaxation time: $10 \mathrm{~s}$.

The following criteria were used to test the joint cartilage [25]: Poisson ratio: 0.5 contact criterion: $0.1 \mathrm{~N}$, predefined indentation amplitude: $0.3 \mathrm{~mm}$, indentation velocity: $0.1 \mathrm{~mm} / \mathrm{s}$, and relaxation time: $10 \mathrm{~s}$.

In order to prevent dehydration of the tissue, we added $\mathrm{NaCl} 0.9 \%$ to the tissue repeatedly using a disposable pipette during the measurement.

\subsection{Thickness Measurement}

The indentation test was followed by a thickness measurement. The indenter for measuring the meniscus was replaced with a size 18 cannula (B. Braun, Melsungen, Germany). The following criteria were selected: stop criterion: $5 \mathrm{~N}$, and speed: $0.5 \mathrm{~mm} / \mathrm{s}$. The cannula was perpendicular to the samples and moved in the direction of the samples at a constant speed. This movement was stopped as soon as the cannula reached the metal below the meniscus. To prevent damage of the load cell, we stopped the cannula at a maximum axial load of $5 \mathrm{~N}$.

The needle technique was also used to measure the thickness of the articular cartilage [28]. The indenter was replaced with a $27 \mathrm{G} \times \frac{3}{4}$ intradermal cannula (B. Braun, Melsungen, Germany). The following criteria were used to measure the thickness of the joint cartilage [25]: stop criterion: $7 \mathrm{~N}$, and speed $0.5 \mathrm{~mm} / \mathrm{s}$. The cannula was perpendicular to the sample and moved at a constant speed until it reached the subchondral bone and the stop criterion was met $[25,26]$.

The thickness mapping used the same measuring grid as the automated indentation mapping in order to get the thickness information on the exact same positions [25].

\subsection{Evaluation of Biomechanical Results}

The findings were analyzed using the software Mach-1 Analysis Version 4.1.0.17 (Biomomentum, Montreal, Canada) and SPSS 25 (IBM, Armonk, NY, USA). The collected data were evaluated according to Sim et al. [26] and Seidenstuecker et al. [25]. The thickness of both the menisci and the articular cartilage was evaluated in the same way. The thickness was calculated as the difference between the first point of contact of the cannula with the tissue, where the load cell registers a load, and the point of transition, where the load cell perceives a load against the stop criterion. The IM was then evaluated at each measuring position using the following formula [31]:

$$
I M=\frac{P}{H} \cdot \frac{1-v^{2}}{2 a k \cdot\left(\frac{a}{h} v\right)}
$$

where IM is instantaneous modulus, $\mathrm{P}$ is load, $\mathrm{H}$ is indentation depth, a is radius of the contact region, $\mathrm{v}$ is Poisson's ratio, $\mathrm{k}$ is correction factor dependent on $\mathrm{a} / \mathrm{h}$ and $\mathrm{v}$ (values of $\mathrm{k}$ were chosen automatically by the software Mach-1 Analysis Version 4.1.0.17 (Biomomentum, Montreal, Canada) according to values determined by Hayes et al. [31] depending on $\mathrm{a} / \mathrm{h}$ and $\mathrm{v})$, and $\mathrm{h}$ is specimen thickness.

\subsection{Statistics}

The data were evaluated using Mach-1 Analysis Software Version 4.1.0.17 (Biomomentum, Montreal, QC, Canada), Origin 2018 Professional (Origin Lab, Northampton, MA, USA), SPSS 25 (IBM, Armonk, NY, USA) and Excel 2016 (Microsoft Corporation, Redmond, WA, USA). The menisci were divided into thirds. The mean value of each third was calculated with Excel 2016 (Microsoft Corporation, Redmond, WA, USA). The mean value of the entire meniscus was calculated as well. Like the meniscus, the meniscus-covered area of the tibial plateau was also divided into thirds. Mean values were then calculated the same way. All biomechanical results were expressed as mean values with a standard deviation. Statistical analysis was conducted with SPSS 25 (IBM, Armonk, NY, USA). Samples were 
compared using the Mann-Whitney $U$ test. Samples were correlated according to Spearman's rank correlation coefficient. Results with $p<0.05$ were considered statistically significant.

After pre-tests of the meniscus, mean values for the maximum applied load of $0.01 \mathrm{~N}$ for arthritis-free samples and $0.03 \mathrm{~N}$ for arthritic samples were expected. The SD was hypothesized as 0.01 . To reach an alpha error level of $1 \%$, at least 11 samples of each (specimen and control) were necessary. The online sample size and power calculator www.dssresearch.com were used. The calculated power for 2 different samples and two-tailed test with a difference of maximum applied load with $0.02 \mathrm{~N}$, 21 samples and 11 controls, SD of 0.01 each, and alpha error level of $1 \%$ was calculated to be $99.7 \%$.

After pre-tests of the cartilage, mean values for the IM of $5 \mathrm{MPa}$ for arthritis-free samples and $3 \mathrm{MPa}$ for arthritic samples were expected. The SD was hypothesized as 1 . To reach an alpha error level of $1 \%$, at least 11 samples of each (specimen and control) were necessary. The online sample size and power calculator www.dssresearch.com were used. The calculated power for 2 different samples and two-tailed test with a difference of IM with $2 \mathrm{MPa}, 21$ samples and 11 controls, SD of $1 \mathrm{MPa}$ each, and alpha error level of $1 \%$ was calculated to be $99.7 \%$.

\section{Results}

\subsection{Biomechanical Results of the Meniscus}

Over the posterior horn, the maximum applied load of the arthritic samples of $0.02 \pm 0.02 \mathrm{~N}$ was significantly greater $(p=0.04)$ than the maximum applied load of the arthritis-free samples of $0.01 \pm 0.01 \mathrm{~N}$ (see Figure 2).

Over the posterior horn, the IM of the arthritic samples of $0.18 \pm 0.1 \mathrm{MPa}$ was not significantly greater $(p=0.17)$ than the IM of the arthritis-free samples of $0.13 \pm 0.07$ (see Figure 2).
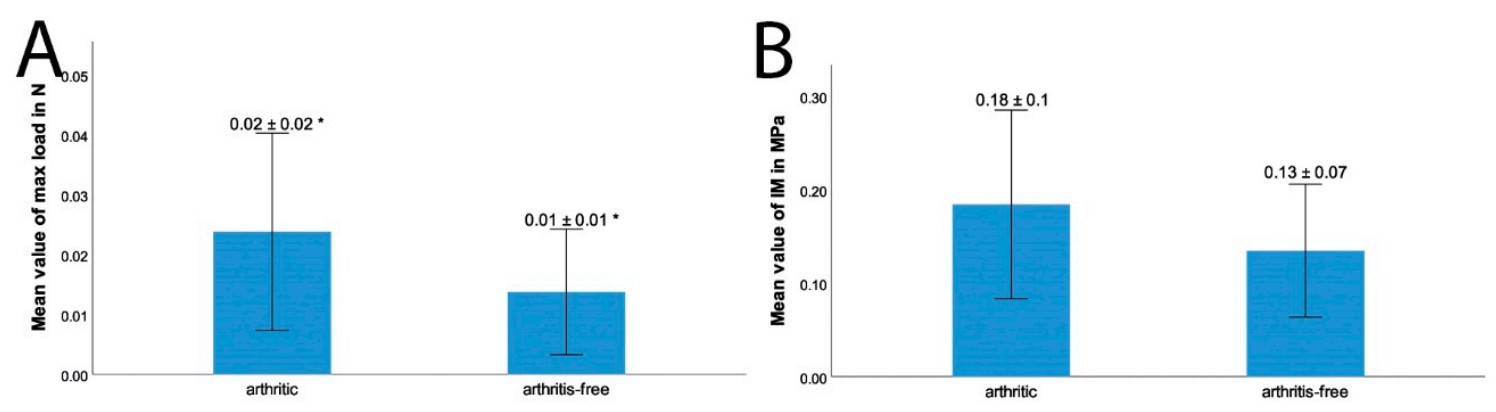

Figure 2. (A) Differences in the maximum applied load in $\mathrm{N}$ over the posterior horn of the meniscus $(p=0.03)$ : arthritic: $0.02 \pm 0.02 \mathrm{~N}$ (error bar: $\pm 1 \mathrm{SD}$ ); arthritis-free: $0.01 \pm 0.01 \mathrm{~N}$ (error bar: $\pm 1 \mathrm{SD})$. (B) Differences in instantaneous modulus (IM) in MPa over the posterior horn of the meniscus: arthritic: $0.18 \pm 0.1 \mathrm{MPa}$ (error bar: $\pm 1 \mathrm{SD}$ ); arthritis-free: $0.13 \pm 0.07 \mathrm{MPa}$ (error bar: $\pm 1 \mathrm{SD}$ ); ${ }^{*}=$ statistically significant with $p<0.05$.

\subsection{Biomechanical Results of the Meniscus-Covered Cartilage Tissue}

Significant differences were found in both the IM and the maximum applied load (see Figure 3) between arthritic and arthritis-free samples at the center of the meniscus-covered articular cartilage. The IM of the arthritic samples with $3.5 \pm 2.02 \mathrm{MPa}$ was significantly smaller than the IM of the arthritis-free samples with $5.17 \pm 1.88 \mathrm{MPa}(p=0.04)$. The maximum applied load of the arthritic samples with $1.04 \pm 0.63 \mathrm{~N}$ was significantly smaller than the maximum applied load of the arthritis-free samples with $1.51 \pm 0.47 \mathrm{~N}(p=0.03)$. 

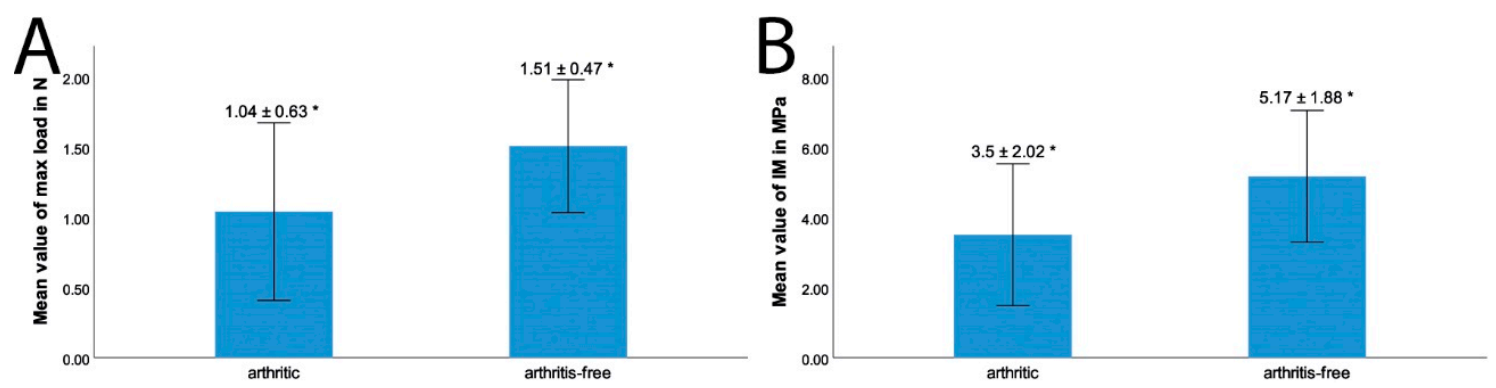

Figure 3. (A): Differences in maximum applied load in $\mathrm{N}$ over the mid part of the meniscus-covered cartilage $(p=0.04)$ ) arthritic: $1.04 \pm 0.63 \mathrm{~N}$ (error bar: $1 \mathrm{SD}$ ); arthritis-free: $1.51 \pm 0.47 \mathrm{~N}$ (error bar: 1SD). (B) Differences in IM in MPa over the mid part of the meniscus-covered cartilage tissue ( $p=0.03)$ : arthritic: $3.5 \pm 2.02 \mathrm{MPa}$ (error bar: $1 \mathrm{SD}$ ); arthritis-free: $5.17 \pm 1.88 \mathrm{MPa}$; ${ }^{*}=$ statistically significant with $p<0.05$.

The maximum applied load over the entire meniscus-covered articular cartilage with $1.06 \pm 0.67 \mathrm{~N}$ was also significantly smaller for the arthritic samples compared to the arthritis-free samples with $1.55 \pm 0.58 \mathrm{~N}(p=0.04)$ (see Figure 4).

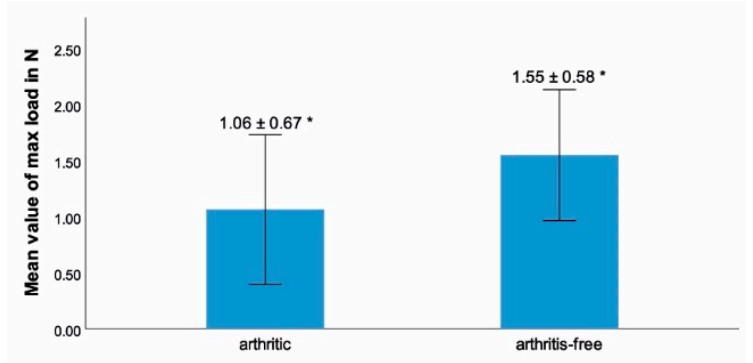

Figure 4. Differences in maximum applied load in $\mathrm{N}$ over the entire meniscus-covered cartilage tissue $(p=0.04)$ : arthritic: $1.06 \pm 0.67 \mathrm{~N}$ (error bar: $1 \mathrm{SD}$ ); arthritis-free: $1.55 \pm 0.58 \mathrm{~N}$ (error bar: $1 \mathrm{SD})$; * = statistically significant with $p<0.05$.

Over the entire meniscus-covered cartilage, the thickness of the arthritic articular cartilage with $2.11 \pm 0.58 \mathrm{~mm}$ was not significantly smaller $(p=0.76)$ compared to the arthritis-free samples with $2.13 \pm 0.42 \mathrm{~mm}$ (see Figure 5). At the mid region of the meniscus-covered cartilage, the thickness of the arthritic cartilage with $2.17 \pm 0.71 \mathrm{~mm}$ was not significantly smaller than the thickness of the arthritis-free cartilage with $2.17 \pm 0.5 \mathrm{~mm}(p=0.82)$.
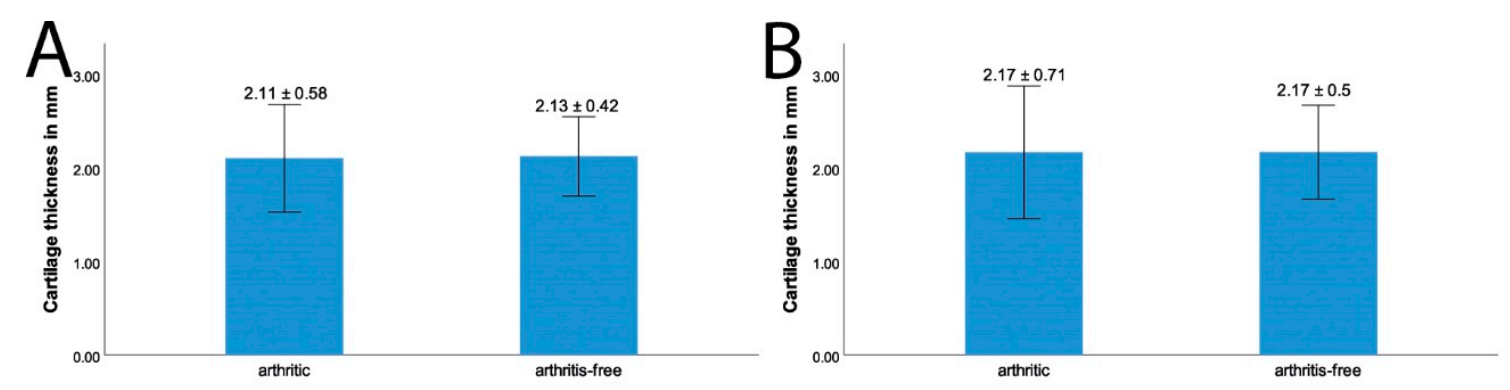

Figure 5. (A) Differences in entire meniscus-covered cartilage thickness in mm: arthritic: $2.11 \pm 0.58 \mathrm{~mm}$; arthritis-free: $2.13 \pm 0.42 \mathrm{~mm}$ (error bar: $1 \mathrm{SD}$ ). (B) Differences in meniscus-covered cartilage thickness in the mid part in mm: arthritic: $2.17 \pm 0.71 \mathrm{~mm}$; arthritis-free: $2.17 \pm 0.5 \mathrm{~mm}$ (error bar: $1 \mathrm{SD}$ ). 


\subsection{Correlation Between the Results of the Meniscus-Covered Cartilage Tissue and the Meniscus}

Only the menisci and their corresponding tibial plateaus were correlated (see Figure 6). Significant correlations were not observed at any point. Neither the maximum applied load nor the IM between the articular cartilage and the corresponding meniscus correlated significantly.

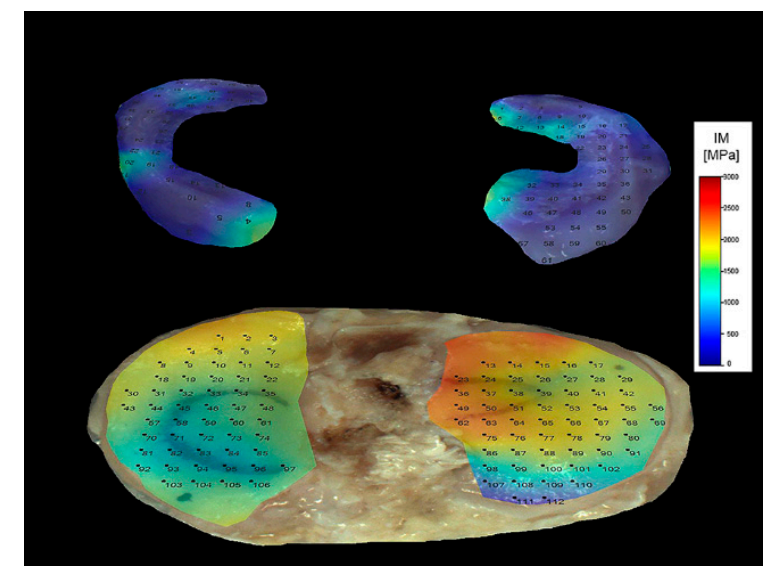

Figure 6. Combined mapping of IM of joint cartilage and associated menisci.

\section{Discussion}

\subsection{Biomechanics of the Meniscus}

The present study showed that the posterior horn is affected in cases of OA. In this study, the maximum applied load on the posterior horn of the arthritic menisci was twice as high as that of the menisci in arthritis-free knees. This means that over the posterior horn, the stiffness of the meniscus increases under arthritis. In relation to the arthritis-free samples, a 100\% higher force was required to indent the arthritic samples to an equal depth $(200 \mu \mathrm{m})$. This can be explained by the special type of rolling-sliding movement in the knee joint [32]. The finding that the posterior horn of the meniscus was affected in knee arthritis is consistent with previous studies. A medial meniscus study showed that the posterior horn carried the highest percentage of shear stress [33]. Warnecke et al. [34] showed by examining degenerative lateral menisci that the highest values for the respective hydraulic permeability " $\mathrm{k}$ " were in the posterior region of the meniscus, indicating that degenerative processes initially occur at the posterior horn. Under increased load, stiffness seems to increase in the particularly stressed regions of the meniscus, i.e., the posterior horn.

\subsection{Biomechanics of the Articular Cartilage}

Both the IM and the maximum applied load at the center region of the articular cartilage covered by the meniscus significantly decreased in arthritis. Degenerative changes are manifested in softening and continuous thinning of the articular cartilage to complete bone baldness [4]. In particular, the central part of the articular cartilage, where local loads are greatest [35] is affected by arthritis [36]. This concerns in particular the uncovered cartilage but also the meniscus-covered regions [36]. With $2.11 \pm 0.58 \mathrm{~mm}$ for arthritic articular cartilage and $2.13 \pm 0.42 \mathrm{~mm}$ for arthritis-free articular cartilage, the cartilage thicknesses were very similar. The values measured for human cartilage tissue of the tibial plateau correspond to the values described in literature on human cartilage tissue of the tibial plateau. Thambyah et al. [37] reported cartilage thicknesses between 3.2 and $3.9 \mathrm{~mm}$ for the meniscus-uncovered parts and between 1.7 and $2.1 \mathrm{~mm}$ for the meniscus-covered areas. Bohringer et al. [38] found a clear difference in cartilage thickness between the different stages of osteoarthritis-cartilage thickness was greatly reduced in severe osteoarthritis. Seidenstuecker et al. [25] found a statistically significant $(p<0.001)$ difference in cartilage thickness between arthritic articular cartilage of the tibial plateau with $2.25 \pm 0.11 \mathrm{~mm}$ and arthritis-free articular cartilage of the tibial plateau with $2.0 \pm 0.07 \mathrm{~mm}$. In this study, 
there was no significant difference in cartilage thickness between arthritic samples and arthritis-free samples. An important task of the meniscus is the protection of the articular cartilage beneath $[5,7,39]$. Due to this protection, the articular cartilage may not have been reduced in the meniscus-covered area even under arthritic conditions. The biomechanical properties of the meniscus-covered articular cartilage decrease under arthritis significantly, although there is no relevant loss of articular cartilage. This means that the cartilage thickness as a structural characteristic of osteoarthritis may be misleading with regard to the interpretation of the biomechanical properties. Previous studies have shown that early stage OA processes occur without macroscopic changes in the cartilage morphology [40,41]. Sim et al. [26] showed that visual and thickness assessments are much less sensitive in distinguishing early degenerated cartilage than mechanical assessments where the functional and structural properties of cartilage play important roles. There are existing non-invasive and non-contact methods to test the biomechanical properties by using ultrasound imaging technologies [42]. Both ultrasound elasticity (UEI) and ultrasound shear wave elasticity imaging (USWEI) have limitations [42]. Therefore, minimally invasive indentation tests could better provide intraoperative information about the severity of joint damage and thus contribute to the decision between joint replacement and joint-preserving therapy.

\subsection{Correlation between the Results of the Meniscus-Covered Cartilage Tissue and the Meniscus}

The IM of the meniscus-covered cartilage tissue was higher for the arthritis-free samples than for the arthritic samples. These observations are consistent with the current literature [25]. For the menisci, the opposite was observed. Both observations can be explained with the changes in the proteoglycan content. In arthritic articular cartilage, proteoglycan synthesis is inhibited in particular by Interleukin-1 $\beta$ [43], whereas more proteoglycan is present in arthritis-free tissue. Proteoglycans bind water and thus stiffen the tissue [44]. In the meniscus, this is the opposite-degenerative or arthritic altered menisci have a higher content of proteoglycan $[45,46]$. In meniscus tissue, an increased glycosaminoglycan content correlates with an increased compression modulus [47]. In addition, the articular cartilage was most affected by arthritis in the central part in contrast to the meniscus, where the posterior horn was mainly affected by arthritis. The finding that the biomechanical results of the articular cartilage did not correlate with those of the meniscus and vice versa appears to be imperative to the background research described above.

\subsection{Weaknesses of This Study}

The arthritis-free samples are a population from the Pathological Institute. The age of the arthritis-free samples is not known. However, it can be assumed that the age is advanced. Degenerative changes occurred. Age-related degenerative changes influence the biomechanical properties of the meniscus and of the articular cartilage. Tsujii et al. [48] showed that age-related compositional changes, such as advanced glycation end-products, largely contribute to tissue stiffness. For the meniscus, age-related changes are at least in tendency comparable to changes caused by osteoarthritis. This also applies to the joint cartilage. Hudelmaier et al. [49] showed that knee cartilage thickness becomes thinner with age. Pataki et al. [50] showed that age leads to impaired synthesis of proteoglycans as well as osteoarthritis. Therefore, the age-related changes and osteoarthritis-related changes are comparable. This reinforces the assumption that osteoarthritis leads to an even greater change in biomechanical properties compared to a healthy young control group than observed in this study. Due to the limited and different number of samples from the arthritic group and the arthritis-free group, further investigations are necessary to determine if the assessment of cartilage thickness as a structural characteristic of osteoarthritis is misleading with regard to the interpretation of articular cartilage's biomechanical properties. Laboratory studies are not fully comparable with in vivo conditions.

\section{Conclusions}

This study is the first to establish a direct connection between biomechanical alterations of the meniscus and the articular cartilage beneath the meniscus under OA by applying an indentation method 
that allows for the examination of the entire tissue. It could be shown that biomechanical changes mainly affect the posterior horn of the meniscus and the middle part of the meniscus-covered joint cartilage. During OA, the stiffness of the meniscus increased while the stiffness of articular cartilage increased. Despite the change in the biomechanical properties of the articular cartilage, no significant difference was found in the thickness of articular cartilage between arthritic and arthritis-free samples. Therefore, the cartilage thickness as a landmark of osteoarthritis may be misleading with regard to the interpretation of the biomechanical properties. Indentation tests may help us to better understand the biomechanical behavior of the meniscus and thus contribute to the further development of meniscus grafts. In addition, minimally invasive indentation tests could provide intraoperative information about the severity of joint damage and thus contribute to the decision between joint replacement and joint-preserving therapy.

Author Contributions: H.O.M., M.S., H.S., and A.B. conceived and designed the experiments; J.P., M.S., S.H.L., and J.W. performed the experiments; J.P. and M.S. analyzed the data; A.B., H.S., and H.O.M. contributed reagents/materials/analysis tools; J.P. and M.S. wrote the paper. All authors have read and agreed to the published version of the manuscript.

Funding: The project was financially supported by Alwin Jäger Foundation. The article processing charge was funded by the Baden-Wuerttemberg Ministry of Science, Research and Art and the University of Freiburg in the funding program Open Access Publishing.

Acknowledgments: The authors would like to thank Arthrex for providing the controls and Melanie L. Hart for proofreading.

Conflicts of Interest: The authors declare no conflict of interest.

\section{References}

1. Heijink, A.; Gomoll, A.H.; Madry, H.; Drobnic, M.; Filardo, G.; Espregueira-Mendes, J.; van Dijk, C.N. Biomechanical considerations in the pathogenesis of osteoarthritis of the knee. Knee Surg. Sports Traumatol. Arthrosc. 2012, 20, 423-435. [CrossRef] [PubMed]

2. Gilbert, S.; Chen, T.; Hutchinson, I.D.; Choi, D.; Voigt, C.; Warren, R.F.; Maher, S.A. Dynamic contact mechanics on the tibial plateau of the human knee during activities of daily living. J. Biomech. 2014, 47, 2006-2012. [CrossRef] [PubMed]

3. Kellgren, J.H.; Lawrence, J.S. Radiological assessment of osteo-arthrosis. Ann. Rheum. Dis. 1957, 16, 494-502. [CrossRef] [PubMed]

4. Bailey, A.J.; Mansell, J.P.; Sims, T.J.; Banse, X. Biochemical and mechanical properties of subchondral bone in osteoarthritis. Biorherology 2004, 41, 349-358.

5. Seedhom, B.B.; Dowson, D.; Wright, V. Proceedings: Functions of the menisci. A preliminary study. Ann. Rheum. Dis. 1974, 33, 111. [CrossRef]

6. Rath, E.; Richmond, J.C. The menisci: Basic science and advances in treatment. Br. J. Sports Med. 2000, 34, 252-257. [CrossRef]

7. Mow, V.C.; Arnoczky, S.P.; Jackson, D.W. Knee Meniscus Basic and Clinical Foundations; Raven Press: New York, NY, USA, 1992; Volume xi, 190p.

8. Berthiaume, M.J.; Raynauld, J.P.; Martel-Pelletier, J.; Labonte, F.; Beaudoin, G.; Bloch, D.A.; Choquette, D.; Haraoui, B.; Altman, R.D.; Hochberg, M.; et al. Meniscal tear and extrusion are strongly associated with progression of symptomatic knee osteoarthritis as assessed by quantitative magnetic resonance imaging. Ann. Rheum. Dis. 2005, 64, 556-563. [CrossRef]

9. Hunter, D.J.; Zhang, Y.Q.; Niu, J.B.; Tu, X.; Amin, S.; Clancy, M.; Guermazi, A.; Grigorian, M.; Gale, D.; Felson, D.T. The association of meniscal pathologic changes with cartilage loss in symptomatic knee osteoarthritis. Arthritis Rheum. 2006, 54, 795-801. [CrossRef]

10. Noyes, F.R.; Barber-Westin, S.D. Repair of complex and avascular meniscal tears and meniscal transplantation. J. Bone Jt. Surg. Am. 2010, 92, 1012-1029.

11. Brittberg, M.; Lindahl, A.; Nilsson, A.; Ohlsson, C.; Isaksson, O.; Peterson, L. Treatment of deep cartilage defects in the knee with autologous chondrocyte transplantation. N. Engl. J. Med. 1994, 331, 889-895. [CrossRef] 
12. Starke, C.; Kopf, S.; Becker, R. Indication and limitations of meniscus replacement. Der Orthopade 2017, 46, 831-838. [PubMed]

13. Joshi, M.D.; Suh, J.K.; Marui, T.; Woo, S.L. Interspecies variation of compressive biomechanical properties of the meniscus. J. Biomed. Mater. Res. 1995, 29, 823-828. [CrossRef] [PubMed]

14. Fithian, D.C.; Kelly, M.A.; Mow, V.C. Material properties and structure-function relationships in the menisci. Clin. Orthop. Relat. Res. 1990, 252, 19-31. [CrossRef]

15. Proctor, C.S.; Schmidt, M.B.; Whipple, R.R.; Kelly, M.A.; Mow, V.C. Material properties of the normal medial bovine meniscus. J. Orthop. Res. 1989, 7, 771-782. [CrossRef] [PubMed]

16. Sweigart, M.A.; Zhu, C.F.; Burt, D.M.; DeHoll, P.D.; Agrawal, C.M.; Clanton, T.O.; Athanasiou, K.A. Intraspecies and interspecies comparison of the compressive properties of the medial meniscus. Ann. Biomed. Eng. 2004, 32, 1569-1579. [CrossRef] [PubMed]

17. Chen, A.C.; Bae, W.C.; Schinagl, R.M.; Sah, R.L. Depth- and strain-dependent mechanical and electromechanical properties of full-thickness bovine articular cartilage in confined compression. J. Biomech. 2001, 34, 1-12. [CrossRef]

18. Franke, O.; Durst, K.; Maier, V.; Goken, M.; Birkholz, T.; Schneider, H.; Hennig, F.; Gelse, K. Mechanical properties of hyaline and repair cartilage studied by nanoindentation. Acta Biomater. 2007, 3, 873-881. [CrossRef]

19. Boschetti, F.; Peretti, G.M. Tensile and compressive properties of healthy and osteoarthritic human articular cartilage. Biorheology 2008, 45, 337-344. [CrossRef]

20. Pereira, H.; Caridade, S.G.; Frias, A.M.; Silva-Correia, J.; Pereira, D.R.; Cengiz, I.F.; Mano, J.F.; Oliveira, J.M.; Espregueira-Mendes, J.; Reis, R.L. Biomechanical and cellular segmental characterization of human meniscus: Building the basis for tissue engineering therapies. Osteoarthr. Cartil. 2014, 22, 1271-1281. [CrossRef]

21. Martin Seitz, A.; Galbusera, F.; Krais, C.; Ignatius, A.; Durselen, L. Stress-relaxation response of human menisci under confined compression conditions. J. Mech. Behav. Biomed. Mater. 2013, 26, 68-80. [CrossRef]

22. Alexopoulos, L.G.; Williams, G.M.; Upton, M.L.; Setton, L.A.; Guilak, F. Osteoarthritic changes in the biphasic mechanical properties of the chondrocyte pericellular matrix in articular cartilage. J. Biomech. 2005, 38, 509-517. [CrossRef] [PubMed]

23. Deneweth, J.M.; Newman, K.E.; Sylvia, S.M.; McLean, S.G.; Arruda, E.M. Heterogeneity of tibial plateau cartilage in response to a physiological compressive strain rate. J. Orthop. Res. 2013, 31, 370-375. [CrossRef] [PubMed]

24. Danso, E.K.; Oinas, J.M.T.; Saarakkala, S.; Mikkonen, S.; Toyras, J.; Korhonen, R.K. Structure-function relationships of human meniscus. J. Mech. Behav. Biomed. Mater. 2017, 67, 51-60. [CrossRef] [PubMed]

25. Seidenstuecker, M.; Watrinet, J.; Bernstein, A.; Suedkamp, N.P.; Latorre, S.H.; Maks, A.; Mayr, H.O. Viscoelasticity and histology of the human cartilage in healthy and degenerated conditions of the knee. J. Orthop. Surg. Res. 2019, 14, 256. [CrossRef]

26. Sim, S.; Chevrier, A.; Garon, M.; Quenneville, E.; Lavigne, P.; Yaroshinsky, A.; Hoemann, C.D.; Buschmann, M.D. Electromechanical probe and automated indentation maps are sensitive techniques in assessing early degenerated human articular cartilage. J. Orthop. Surg. Res. 2017, 35, 858-867. [CrossRef]

27. Sim, S.; Hadjab, I.; Garon, M.; Quenneville, E.; Lavigne, P.; Buschmann, M.D. Development of an electromechanical grade to assess human knee articular cartilage quality. Ann. Biomed. Eng. 2017, 45, 2410-2421. [CrossRef]

28. Jurvelin, J.S.; Räsänen, T.; Kolmonens, P.; Lyyra, T. Comparison of optical, needle probe and ultrasonic techniques for the measurement of articular cartilage thickness. J. Biomech. 1995, 28, 231-235. [CrossRef]

29. ISO. 14577-1 Metallic Materials-Instrumented Indentation Test for Hardness and Materials Parameters-Part 1: Test Method; ISO: Geneva, Switzerland, 2015.

30. Zhou, Y.; Tang, Y.; Hoff, T.; Garon, M.; Zhao, F.Y. The verification of the mechanical properties of binder jetting manufactured parts by instrumented indentation testing. Procedia Manuf. 2015, 1, 327-342. [CrossRef]

31. Hayes, W.C.; Keer, L.M.; Herrmann, G.; Mockros, L.F. A mathematical analysis for indentation tests of articular cartilage. J. Biomech. 1972, 5, 541-551. [CrossRef]

32. Kummer, B. Biomechanik: Form und Funktion des Bewegungsapparates Mit 3 Tabellen; Dt. Ärzte-Verl.: Köln, Germany, 2005; Volume XV, p. 604 S.

33. Walker, P.S.; Arno, S.; Bell, C.; Salvadore, G.; Borukhov, I.; Oh, C. Function of the medial meniscus in force transmission and stability. J. Biomech. 2015, 48, 1383-1388. [CrossRef] 
34. Warnecke, D.; Balko, J.; Haas, J.; Bieger, R.; Leucht, F.; Wolf, N.; Schild, N.; Stein, S.; Seitz, A.; Ignatius, A.; et al. Degeneration alters the biomechanical properties and structural composition of lateral human menisci. Osteoarthr. Cartil. 2020, 28, 1482-1491. [CrossRef] [PubMed]

35. Bae, J.Y.; Park, K.S.; Seon, J.K.; Kwak, D.S.; Jeon, I.; Song, E.K. Biomechanical analysis of the effects of medial meniscectomy on degenerative osteoarthritis. Med. Biol. Eng. Comput. 2012, 50, 53-60. [CrossRef] [PubMed]

36. Pelletier, J.P.; Raynauld, J.P.; Berthiaume, M.J.; Abram, F.; Choquette, D.; Haraoui, B.; Beary, J.F.; Cline, G.A.; Meyer, J.M.; Martel-Pelletier, J. Risk factors associated with the loss of cartilage volume on weight-bearing areas in knee osteoarthritis patients assessed by quantitative magnetic resonance imaging: A longitudinal study. Arthritis Res. Ther. 2007, 9, R74. [CrossRef] [PubMed]

37. Thambyah, A.; Nather, A.; Goh, J. Mechanical properties of articular cartilage covered by the meniscus. Osteoarthr. Cartil. 2006, 14, 580-588. [CrossRef]

38. Bohringer, M.E.; Beyer, W.F.; Weseloh, G. Comparative histomorphometry of subchondral bone density and articular cartilage thickness in the tibial head in early human arthritis. Z. Orthop. Ihre Grenzgeb. 1995, 133, 291-302.

39. Fischenich, K.M.; Lewis, J.; Kindsfater, K.A.; Bailey, T.S.; Haut Donahue, T.L. Effects of degeneration on the compressive and tensile properties of human meniscus. J. Biomech. 2015, 48, 1407-1411. [CrossRef]

40. Burstein, D.; Gray, M.; Mosher, T.; Dardzinski, B. Measures of molecular composition and structure in osteoarthritis. Radiol. Clin. N. Am. 2009, 47, 675-686. [CrossRef]

41. Crema, M.D.; Roemer, F.W.; Marra, M.D.; Burstein, D.; Gold, G.E.; Eckstein, F.; Baum, T.; Mosher, T.J.; Carrino, J.A.; Guermazi, A. Articular cartilage in the knee: Current $\mathrm{mr}$ imaging techniques and applications in clinical practice and research. Radiographics 2011, 31, 37-61. [CrossRef]

42. Kim, K.; Wagner, W.R. Non-invasive and non-destructive characterization of tissue engineered constructs using ultrasound imaging technologies: A review. Ann. Biomed. Eng. 2016, 44, 621-635. [CrossRef]

43. Evans, C.H.; Robbins, P.D. Potential treatment of osteoarthritis by gene therapy. Rheum. Dis. Clin. N. Am. 1999, 25, 333-344. [CrossRef]

44. Lüllmann-Rauch, R. Taschenbuch Histologie 5; vollst. überarb. Auflage ed. 5; Thieme: Stuttgart u.a, Germany, 2015; Volume XVIII, p. 726 S.

45. Sun, Y.; Mauerhan, D.R.; Kneisl, J.S.; James Norton, H.; Zinchenko, N.; Ingram, J.; Hanley, E.N., Jr.; Gruber, H.E. Histological examination of collagen and proteoglycan changes in osteoarthritic menisci. Open Rheumatol. J. 2012, 6, 24-32. [CrossRef] [PubMed]

46. Herwig, J.; Egner, E.; Buddecke, E. Chemical changes of human knee joint menisci in various stages of degeneration. Ann. Rheum. Dis. 1984, 43, 635-640. [CrossRef] [PubMed]

47. Bursac, P.; Arnoczky, S.; York, A. Dynamic compressive behavior of human meniscus correlates with its extra-cellular matrix composition. Biorheology 2009, 46, 227-237. [CrossRef] [PubMed]

48. Tsujii, A.; Nakamura, N.; Horibe, S. Age-related changes in the knee meniscus. Knee 2017, 24, 1262-1270. [CrossRef]

49. Hudelmaier, M.; Glaser, C.; Hohe, J.; Englmeier, K.H.; Reiser, M.; Putz, R.; Eckstein, F. Age-related changes in the morphology and deformational behavior of knee joint cartilage. Arthritis Rheumatol. 2001, 44, 2556-2561. [CrossRef]

50. Pataki, A.; Ruttner, J.R.; Abt, K. Age-related histochemical and histological changes in the knee-joint cartilage of c57b1 mice and their significance for the pathogenesis of osteoarthrosis. I. Oxidative enzymes. Exp. Cell Biol. 1980, 48, 329-348. [CrossRef]

Publisher's Note: MDPI stays neutral with regard to jurisdictional claims in published maps and institutional affiliations.

(C) 2020 by the authors. Licensee MDPI, Basel, Switzerland. This article is an open access article distributed under the terms and conditions of the Creative Commons Attribution (CC BY) license (http://creativecommons.org/licenses/by/4.0/). 